\title{
EL SISTEMA BENEFICIAL EN LA BARCELONA DEL SEGLE XIV LA CONJUNCIÓ DE LA RELIGIOSITAT, L'ECONOMIA I L'ART
}

\section{CRISTINA BORAU I MORELL}

\begin{abstract}
SUMARI
I. Elements definitoris del benefici eclesiàstic.- II. Figures implicades en el benefici eclesiàstic: II.1. El fundador. II.2. El beneficiat. II.3. El patró.- III. Sistemes de finançament del benefici, la capella i el retaule: III.1. Finançament del benefici. III.2. Finançament de la capella. III.3. Finançament dels ornaments beneficials.- IV. Supervisió de l'estat de la capella, el funcionament del benefici i el comportament del beneficiat.- V. Possibles situacions del benefici al llarg del temps.
\end{abstract}

El benefici eclesiàstic era un ens que, per la complexitat del seu funcionament, es trobava connectat a alguns dels aspectes més importants del seu entorn social, de manera que van confluir en ell fenòmens tan diferents com la religiositat, l'economia i l'art. L'auge d'aquesta confluència es va manifestar particularment en la Barcelona del segle XIV, moment en què, dins d'un context de renovació global de la ciutat, es van realitzar les ampliacions de la Seu i de les tres grans esglésies parroquials: Santa Maria del Mar, Santa Maria del Pi i Sant Just. Aquell període va discórrer sota el signe de la dualitat, entre la prosperitat dels que s'havien enriquit amb la puixança del comerç i de la monarquia, i la successió de crisis bèl-liques, d'abastiments $\mathrm{i}$ epidèmiques que van provocar l'endeutament de les institucions. El finançament de les obres de la Seu i les esglésies parroquials en el marc del sistema beneficial va constituir un reflex de la situació socioeconòmica del seu entorn: la manca de solvència de les juntes d'obra

"Anuario de lsstudios Medievales". 28 (1998) 
d'aquelles esglésies contrastava amb la riquesa d'alguns dels particulars que sol-licitaven permís per a fundar un benefici en elles. D'aquesta manera, com succeïa en l'àmbit seglar, l'única possibilitat d'enfrontar el cost d'aquelles obres va ser la venda de drets sobre part d'elles, és a dir, la concessió de capelles a alguns fundadors beneficials a canvi d'importants donatius. Així, mentre el dot atorgat al benefici per al seu funcionament el connectava a la trama econòmica del seu entorn, les capelles i els retaules finançats en nom seu el connectaven a l'àmbit de la promoció artística, d'aquí que representi la conjunció de la religiositat, l'economia i l'art.

\section{ELEMENTS DEFINITORIS DEL BENEFICI ECLESIÀSTIC}

El dret canònic defineix el benefici eclesiàstic com un ens jurídic amb finalitat religiosa, vàlid a perpetuïtat, i també com un dret inalienable. El benefici es concretava en la seva adscripció a un altar erigit sota l'advocació d'un sant, la celebració quotidiana en ell de l'ofici sagrat, d'acord amb l'horari canònic, i l'assignació perpètua d'unes rendes que garantissin el seu funcionament. L'àmbit del benefici eclesiàstic era molt ampli: des de les catedrals, passant per les esglésies parroquials, les de convents (com el de Sant Francesc de Barcelona) ${ }^{1}$ i monestirs (com el de Sant Pere de les Puel-les) ${ }^{2}$, fins a les capelles d'hospitals, com les dels fundats per Bernat Marcús i Pere Desvilar ${ }^{3}$ o d'altres institucions benèfiques, com el refectori de la Pia almoina de la $\mathrm{Seu}^{4}$. La fundació d'un benefici constituïa un acte legítim, realitzat mitjançant la signatura d'un contracte ("dotalia") en què s'especificaven, bàsicament, el lloc on s'erigia, els drets i obligacions del sacerdot encarregat de la celebració litúrgica ("beneficiat") i les rendes que li atorgava el fundador ("dot"). També s'hi feia constar la identitat del beneficiat, o bé la branca familiar del fundador a què havia de pertànyer, tant ell com els seus successors. El mateix succeïa amb la persona designada com patrona del benefici, tot i que, de vegades, si el fundador realitzava la institució en vida, podia reservar-se per a ell el

\footnotetext{
'AHPB, P. Ullastrell, 22/3, fol.12 r. febrer 1382.

'AHMSPP, Llibres de Visita, 1, 1572, fols. 24 i 26.

${ }^{3} \mathrm{ACB}$, Speculum, II, fols. $197 \mathrm{r}$ i $214 \mathrm{r}$.

${ }^{4} \mathrm{ACB}$, Speculum, I, fol. $807 \mathrm{r}$.
} 
dret de patronat. Igualment, també se solia especificar en aquests documents l'advocació a què es dedicava el benefici, tot i que, quan es tractava de fundacions ordenades en testaments, de vegades aquest aspecte es deixava a criteri dels marmessors.

Tant l'arxiu episcopal com el de l'església on s'instituïa el benefici havien de conservar un exemplar d'aquests documents fundacionals, així com els fundadors i els notaris que els havien redactat. D'aquesta manera, tots els implicats en la fundació i en la signatura del contracte, així com els seus successors, podien reclamar el compliment del que s'hi havia estipulat, en el cas que alguna de les parts ho incomplís. Així consta en l'acta de dotació del benefici instituït, l'any 1353, pel mercader Jaume de Rocafort al claustre de la Seu':

\begin{abstract}
In super convenio et promitto vobis, dicto Raymundo Çator ac domino episcopo Barchinone et eius venerabili vicario (...) et venerabili Capitulo dicte Sedis Barchinone ac vobis etiam, notario infrascripto (...), quod predicta omnia et singula attendam et complebo et tenebo et observabo imperpetuum, et quod in aliquo non contraveniam aliquo iure, causa vel etiam racione (...) Ad hec nos. Franciscus Rufani. vicarius generalis in spiritualibus et temporalibus reverendi in Christo Patris et Domini domini Michaelis. miseracione divina episcopi Barchinone, in remotis agente. et nos. Capitulum dicte Sedis Barchinone (...), gratis et ex certa sciencia convenimus et promittimus vohis. dicto Jacobo de Rochaforti, et vestris quod predictam assignacionem loci et capelle quam vobis fecimus. ut superius est dictum. tenebimus et observabimus imperpetuum vobis et rectori seu beneficiato dicti presbiteratus (...) Et volumus nos. dicti contrahentes, quod de predictis fiant et fieri possint. tam nobis et utrique nostrum quam dicto rectori seu beneficiato dicti presbiteratus, tot originalia et publica instrumenta, quot inde petierimus et habere voluerimus, per notario infrascriptum
\end{abstract}

Podem veure, doncs, que la institució d'un benefici tenia com objectiu la manutenció d'un prevere dedicat, exclusivament i a perpetuïtat, a la celebració de l'ofici diví en l'altar erigit al sant venerat pel fundador. La finalitat de sufragar aquestes celebracions era, sobretot, propiciar la intercessió d'aquell sant davant Déu per la salvació de l'ànima del benefactor, ja que, en molts casos, les fundacions beneficials eren ordenades en testaments, però, com veurem, també podia ser la d'afavorir amb les rendes

${ }^{5} \mathrm{ADB}$, Registra Dotaliarum, 1, fols. 330 v-333 v. 2-1-1353. 
beneficials algun prevere familiar o amic. També podem observar que aquestes fundacions havien de comptar amb el consentiment de l'autoritat competent: en primer lloc, del bisbe, i en segon lloc, segons l'església on s'efectués, del Capítol, l'ardiaca o el vicari perpetu, o el rector. Igualment, podem veure que l'obtenció d'aquest consentiment depenia del fet que es pogués aportar un dot suficient per a la manutenció del prevere designat com beneficiat ("qui altari servit, de altari vivere debet"), la provisió del parament litúrgic necessari per a oficiar les misses, i la commemoració de les dates significatives en relació al benefici, com la festivitat del sant titular o l'aniversari del traspàs del fundador.

Les rendes percebudes sobre els béns que integraven aquells dots eren el que vinculava el benefici eclesiàstic al funcionament econòmic del seu entorn social, però, com s'ha dit, durant el període en què ens centrem, el segle XIV, tant la ciutat de Barcelona com les seves esglésies es trobaven en ple procés de transformació, de manera que els fundadors beneficials no sempre podien disposar de capella on erigir el seu benefici. Aquesta situació, unida a les dificultats de finançament d'aquelles obres, va donar lloc que, tant el capítol catedralici com les juntes d'obra parroquials optessin per canalitzar la devoció dels fundadors més rics cap a la promoció de capelles, que els eren concedides a canvi de generosos donatius. Un cop construïda la capella, erigit l'altar, atorgat el dot $\mathrm{i}$ investit el beneficiat, no era imprescindible però sí recomanable que, d'alguna manera, apareguessin visualitzats la vida i miracles del sant titular del benefici i la capella, com guia i exemple per als fidels. D'aquí que aquest procés conclogués amb la contractació d'un retaule, de manera que el benefici no només estava vinculat al funcionament econòmic del seu entorn, sinó també al finançament d'obres d'art.

\section{FIGURES IMPLICADES EN EL BENEFICI ECLESIÀSTIC}

La institució d'un benefici eclesiàstic no només depenia de la iniciativa del fundador, sinó que també requeria la designació, per part seva, de dues figures bàsiques per al seu funcionament: d'una banda, la del prevere responsable de celebrar l'ofici díví en l'altar al que estava adscrit; de l'altra, la de l'encarregat del seu govern i administració. D'aquesta manera, les figures implicades en la institució i el funcionament del benefici eren tres: fundador, beneficiat i patró beneficial. 


\section{II.1. El fundador}

L'objectiu del fundador d'un benefici era, bàsicament, la manutenció d'un prevere dedicat exclusivament a pregar per la salvació de la seva ànima, ja que, com s'ha dit, la major part de fundacions es devien a disposicions testamentàries. En el cas de les fundacions realitzades en vida del fundador, cal suposar que l'objectiu era també el d'atreure's la protecció del sant titular del benefici a través de la pregaria quotidiana del beneficiat. El perfil del fundador variava, bàsicament, en funció de dos factors: el primer estava en funció del moment en què s'efectuava la fundació, i el segon, que aquesta es realitzés sota l'advocació d'un sant que tingués capella dedicada o no. Pel que fa al primer factor, fins començaments segle XIV, sobretot a la Seu, van predominar les fundacions realitzades per eclesiàstics (concretament bisbes i canonges), però cap a mitjans segle es van anar veient desplaçades per les de mercaders i oficials reials. Pel que fa al segon factor, les fundacions dedicades a sants que no tenien capella podien comportar que el fundador del primer benefici instituït sota aquella advocació financés la seva construcció, cosa impensable si no hagués gaudit d'una bona situació econòmica. En canvi, a remolc d'aquelles primeres fundacions vinculades al finançament de les capelles, se'n produïen altres instituïdes per fundadors amb menys recursos, ja que no era el mateix haver de dotar un benefici que, a més, haver de sufragar la construcció d'una capella.

Els drets del fundador beneficial consistien, doncs, a disposar a perpetuïtat d'un prevere que pregués per la seva salvació eterna i la dels seus familiars en l'altar de la capella escollida, i a poder-lo elegir i estipular les seves obligacions, com va fer el mercader Guillem Almogàver, promotor d'una capella de la Seu, en el seu testament l'any $1367^{6}$ :

(...) statuens et mandans quod preshiter seu rector dicti preshiteratus, singulis diebus, celebret ibi missam et interesit in dicta Sede omnibus divinis officiis, diurnis periter et nocturnis, et in suis missis, oracionibus et divinis officiis et alia oret ad Deum pro animabus meam et omnium predictorum fidelium quorumcumque

'ADB, Registra Dotaliarum, 1, fol. 295 v, 3-7-1367. 
També consistien en la potestat d'elegir el patró beneficial, tot i que el fundador, si instituiia el benefici en vida, es podia reservar el dret de patronat per a ell; en la de contractar un retaule per a l'altar del benefici i en la de poder fer-hi pintar l'escut familiar, drets que van ser concedits a Jaume de Rocafort, juntament amb una capella del claustre de la Seu, l'any $1353^{7}$ :

Concedimus et assignamus (...) quandam capellam que noviter sit et construitur (...) Concedimus etiam vobis licenciam atque damus quod vos possitis in dicta capella, et ad servicium eiusdem, facere cortinas, palis, et reataules cum signis vestris

Igualment, també se li concedia el dret a ser enterrat a la capella i, en el cas que hagués sufragat la seva construcció, el de poder posar l'escut familiar en els seus murs, drets concedits als marmessors testamentaris de Francesc d'Eiximenis, juntament amb una altra de les capelles d'aquell claustre, l'any $1355^{8}$ :

in dicta capella possitis (...) facere signum et signa, tot et tanta ac alia quot et quanta volueritis (...) et etiam carnerium

Les obligacions del fundador consistien a atorgar un dot que produís rendes suficients per a garantir la manutenció del beneficiat i el funcionament del benefici, requisit indispensable per a obtenir el permís de fundació; la presentació del beneficiat a l'autoritat eclesiàstica, en el cas que es reservés el dret de patronat mentre visqués; i, finalment, segons les notícies aportades per algun dels llibres de visita pastoral, la d'encarregar un retaule per a la capella del benefici, en el cas que no n'hi hagués, de manera que no resulta del tot clar fins quin punt constituïa un dret o una obligació del fundador. Així va ser ordenat a l'hereu del fundador beneficial Jaume de Rocafort, al qual ja ens hem referit anteriorment"

Vocetur en Rochafort, pater primi beneficiati, quis tenetur facere fieri retrotabulum in dicta capella

\footnotetext{
${ }^{7} \mathrm{ACB}$. Notaria particular, F.de Puig, 238, s.f., 3-1-1353.

${ }^{8}$ ACB. Notaria particular, F.de Puig, 240, s.f., 3-3-1355.

"ADB, Visites Pastorals, 9. 1388, Seu, fol. 26 v.
} 


\section{II.2. El beneficiat}

El benefici eclesiàstic ha estat el modus vivendi de la gran majoria dels sacerdots fins pràcticament l'època actual. En conseqüència, la garantia de subsistència que podia comportar feia que els fundadors es decantessin gairebé sempre per l'afavoriment de sacerdots familiars i amics. Segons les notícies aportades per la documentació, el perfil predominant de beneficiat era el del prevere jove, que acabés de completar els seus estudis i de ser ordenat, ja que, com era el que més necessitava situar-se, solia ser el més afavorit pels fundadors. En alguna ocasió podia tractar-se de joves que, després d'haver residit amb el futur fundador d'un benefici com a preceptors dels seus fills, eren designats beneficiats quan decidia fundar-lo, per tal que, després de complir la seva missió educativa i ser ordenats sacerdots, tinguessin l'existència assegurada. Aquesta va ser la intenció del mercader Guillem Almogàver, promotor d'una capella de la Seu, al qual ja ens hem referit abans ${ }^{10}$ :

\footnotetext{
et dimitto seu assigno, cum presenti, dictum altare seu presbiteratum, cum suis iuribus universis, Raymundo Ferrarii, scolari mecum comoranti, pedagogo seu instructori subscriptorum filiorum meorum, qui, quando primum comode poterit, se faciat in prebiterum promoveri et interim faciat dictum servicium dicti altaris pro ydoneum substitutum.
}

Els drets del beneficiat consistien, doncs, a ser presentat pel patró beneficial a l'autoritat eclesiàstica per a obtenir la investidura del benefici; en tenir la custòdia dels ornaments i el parament litúrgic del benefici, que li era tramesa en el moment de la investidura; a rebre els documents acreditatius dels drets a percebre la renda sobre els béns assignats al benefici; en la percepció d'aquelles rendes en els moments anuals estipulats pel fundador; $i$, finalment, en el gaudiment de tot això a perpetuïtat. Però, de vegades, amb el pas del temps i la progressiva barreja de la branca familiar designada pel fundador amb altres famílies, es podia arribar a desconèixer a qui pertocava ser investit com a beneficiat quan el benefici quedava vacant. Aquesta situació apareix contemplada en alguns dels documents fundacionals, on s'estipulava la publicació de la vacant del benefici i la convocatòria de

\footnotetext{
${ }^{10} \mathrm{ADB}$, Registra Dotaliarum, 1, fol. 296 r, 3-7-1367.
} 
tots els possibles candidats amb dret a ser investits beneficiats, que havien de comparèixer en el termini d'un mes, per tal de poder decidir quin d'ells tenia més drets en la línia successòria.

La documentació notarial proporciona algunes notícies relatives a la cerimònia d'investidura o confirmació de beneficiats, com la del prevere Ferrer, que va rebre la confirmació d'un dels beneficis de sant Bartomeu instituits a la Seu el maig del $1401^{11}$ :

(...) de beneficio ipso sancti Bartholomei, quam traddit hoc modo, scilicet, quod intrarunt intus capellam sancti Bartholomei, constructam in claustro Sedis Barchinone, et posuit manus ipsius Ferrarii super altare et tradidit sibi calicem, vestimentam et missale, de quibus peciis dictus venerabilis Ferrarius sibi fieri unum et plura publica instrumenta

Les obligacions del beneficiat consistien, bàsicament, en la celebració quotidiana de l'ofici diví en l'altar del benefici, d'acord amb l'horari canònic; a sol-licitar permís al patró del benefici per a arrendar o vendre els drets i propietats que produien les rendes beneficials, ja que el dret a percebre-les no comportava el control de les fonts que les produïen; $\mathrm{i}$ finalment, a vetllar per la conservació dels ornaments beneficials, ja que, quan s'investia un nou beneficiat (per renúncia o defunció de l'anterior) el seu predecessor o els seus marmessors li feien signar un rebut on apareixien inventariats els objectes que li trametien, de manera que si desapareixia algun d'aquells objectes, per negligència, per empenyorament il-lícit o per la causa que fos, es podia identificar el responsable i alliberar l'innocent de tota sospita. Així ho va fer el beneficiat de l'altar dels sants Marc i Bàrbara de Santa Maria del Mar amb el seu successor l'any $1370^{12}$ :

(...) in presencia Raymundi Rosselli, scriptoris iurati sub me, Ffrancisco de Relato, regia auctoritate notario, (...) G. Cerola, prebiter beneficiatus in ecclesia Beate Marie de Mari Barchinone, in altari sancti Marchi et sancte Barbere constructo in dicta ecclesia, tradidit Jacobi Cerdani, prebitero nunc benefficiato in altaris, res sequentes que sunt dicti benefficii: Primerament, -I missal nou. Ítem, un calçer d'argent daurat ab senyal de Serra. Ítem, Icoxí obrat de seda", etc., etc.

"ACB, Notaria particular, G.Canyelles, 271, fol. 58 r, maig del 1401.

${ }^{12} \mathrm{AHPB}, \mathrm{F}$. de Relat, 27/1, fol. 127 v, 6-4-1370. 
Pel que fa als ornaments, com en el cas dels fundadors, no resulta clar fins quin punt la contractació d'un retaule per a la capella del benefici podia constituir un dret o una obligació per al beneficiat. La documentació notarial proporciona notícies sobre retaules contractats per beneficiats i, fins i tot, sobre encàrrecs realitzats conjuntament per tots els existents en una capella, com va succeir en la de sta. Maria Magdalena de la Seu l'any $1370^{13}$. En els llibres de visita pastoral del període que ens ocupa no es fa referència a l'obligació de cap beneficiat d'haver d'encarregar un retaule, però si a la d'encarregar altres objectes per a la capella, com la que tenia el beneficiat de l'altar de sant Jaume de la Seu l'any $1388^{14}$ :

Item. quod faciat fieri unum pallium et unum frontale ad opus dicti altaris.

hinc ad unum annum proximum secuturum

\section{II.3. El patró}

Com el beneficiat, el patró solia ser designat entre els membres d'una de les branques familiars del fundador, tot i que aquest també podia reservar-se el dret de patronat per a ell mentre visqués o bé atorgar-lo a alguna corporació o dignitat eclesiàstica. El seu perfil era, doncs, tan variat com el del fundador. Si aquell designava el patró entre els seus parents, tant podien ser-ho els hereus, l'hereu universal com l'hereu del mas d'on procedia la família, opció presa pel mercader Guillem de Prexana, fundador d'un benefici a Santa Maria del Mar l'any $1332^{15}$. En canvi, si el designava entre les corporacions o dignitats vinculades a l'església on fundava el benefici, podia ser-ho un ardiaca, com en el benefici instituit per Bernat Llull, ardiaca de Santa Maria del Mar, l'any $1348^{16}$; un vicari perpetu, com en el fundat per Bernat Sabater, vicari perpetu d'aquella església, l'any $1363^{17}$ : un rector. com en el benefici ordenat en el testament de Jaume de Santcliment a Sant Just l'any $1345^{18}$; uns hebdomedaris, com en el benefici

\footnotetext{
1:AHPB, R. de Massana, 28/5. s.t.. 13-9-1370. Publical per Josep Ma Madurell. El pintor Lluis Borrassà. III. Barcelona, 1952, p. 58. doc. 443.

${ }^{14}$ ADB, Visites Pastorals, 9. 1388. Seu. fol. 24 r.

${ }^{15} \mathrm{ACB}$, Speculum. II. fol. $175 \mathrm{r}$

${ }^{16} \mathrm{ACB}$, Speculum, II, fol. $161 \mathrm{r}$.

${ }^{17} \mathrm{ACB}$. Speculum, II, fol. $137 \mathrm{r}$.

${ }^{18} \mathrm{ACB}$, Speculum, II, fol. 432 r.
} 
fundat per Arnau Sescomes, bisbe de Lleida, a Santa Maria del Mar l'any $1329^{19}$, etc.

Els drets del patró consistien, bàsicament, a poder autoritzar o prohibir la renúncia del beneficiat designat pel fundador a favor d'un altre prevere aliè a la família, per causa de permuta del seu benefici amb el d'aquell, així com en la facultat d'aprovar o impedir l'arrendament i la venda dels béns adscrits al benefici. Les seves obligacions consistien en la presentació del candidat a l'autoritat eclesiàstica perquè fos investit beneficiat, a assegurar-se que percebés les rendes destinades a la seva manutenció regularment i a gestionar profitosament les propietats adscrites al benefici a través del dot atorgat pel fundador. Tots aquests drets i obligacions s'especifiquen clarament en el testament de Sibil·la, dona del mercader Raimon Sarroca, fundadora d'una capellania a l'altar major de Santa Maria del $\mathrm{Mar}^{20}$ :

E jaquesch lo ius patronat del dit presbiterat a la dona na Francescha. muller del dit Macià de Thesarac. de tota vida sua e aprés son òbit als administradors o procuradors de l'acaptiri del baci dels pobres vergonyants de la dita esglea de Santa Maria de la Mar. qui aquell presbiterat degen assignar, eytantes vegades que vegarà. a un prevere o scolà de linage meu (...) e que lo dit prebere haje las ditas quinse lliures. e aquelles deye haver e rebre quescun any perpètuo per mà de la dita dona na Francesca de ment que viurà. e aprés son òbit per mans dels dits procuradors e administradors del dit acaptiri dels pobres vergonyants (...) Los romanents vuytanta sous sian de la dita dona Ffrancescha de tota sa vida. e aprés son òbit dels dits procuradors e administradors del dit acaptiri. quals que sian. per lurs trebayls. E los dits Francescha. de ça vida. e aprés los dits administradors. degen rebre les dites vint lliures de censal mort e aquelles convertir segons demunt he ordenat $(\ldots)$

\section{SistemES DE FINANÇAMENT DEL BENEFICI, LA CAPELLA I EL RETAULE}

Com veiem, la celebració del culte comportava una despesa considerable, ja que requeria la disponibilitat d'uns elements indispensables per a poder-se realitzar: el prevere, la capella i el parament litúrgic. La

\footnotetext{
${ }^{19} \mathrm{ACB}$. Speculum. II. fol. $62 \mathrm{r}$.

"ADB. Registra Dotaliarum. 2. fol. 585 r., 26-8-1381.
} 
provisió d'aquests elements estava contemplada, estipulada i garantida per l'organització del culte a través del sistema beneficial, però les seves característiques, el seu cost i, per tant, els recursos emprats per a finançarlos eren diferents.

\section{III.1. Finançament del benefici}

Com ja s'ha dit, el benefici era un ens jurídic vàlid a perpetuïtat, de manera que calia garantir el seu funcionament, de forma ininterrompuda, durant el màxim de temps possible. La manera d'assegurar-ho era dotar-lo amb una renda que produís uns ingressos periòdics i segurs, en teoria poc sensibles a les fluctuacions econòmiques. Això es realitzava mitjançant inversions en títols de deute públic, com censals i violaris, o a través d'altres sistemes més tradicionals, com la percepció de drets sobre propietats urbanes i rurals a partir de contractes emfitèutics. La mitjana de l'import de les rendes anuals dels beneficiats durant el segle XIV estava, a la Seu i a les tres grans esglésies parroquials de Barcelona, al voltant de les 20 lliures, de manera que, prèviament, s'havien d'haver atorgat drets i propietats al benefici que, sumats, proporcionessin rendes per aquell valor. La renda beneficial més alta de què es té notícia és l'atorgada, l'any 1387, per Pere Safont, un apotecari convertit en riquíssim mercader que va promoure una capella a la Seu: 35 lliures $^{21}$. Però, generalment, aquelles rendes s'havien d'anar actualitzant al cap dels anys, perquè si no s'acabaven devaluant $i$ esdevenien insuficients per a mantenir el beneficiat i sufragar les despeses relacionades amb el benefici, com. per exemple, les celebracions anuals ordenades pel fundador.

La situació econòmica de l'entorn del benefici va influir, durant el període estudiat, en l'elecció dels sistemes adoptats per al seu finançament. D'aquesta manera, des de mitjans segle XIV, moment en què es va iniciar la successió de crisis que van provocar l'endeutament de les institucions i els organismes de govern (mentre, en canvi, alguns particulars havien aconseguit fortunes impressionants), el censal, tant mort com redimible, va començar a formar part dels dots beneficials o, fins i tot, a constituir-ne l'única font d'ingressos. Aquest és el cas del dot atorgat pel mercader Gilabert de Fàbrega, promotor d'una de les capelles de Santa Maria del Mar, al seu

\footnotetext{
"ADB, Registra Dotaliarum. 1. fols. 398 r.-409 r.
} 
benefici l'any 1363: 1000 sous en censal mort sobre la universitat de Barcelona i 500 sous en violari sobre la de Perpinyà ${ }^{22}$, que proporcionaven, descomptant altres despeses, 15 lliures de renda al beneficiat. Igualment, la documentació consultada proporciona alguna notícia relativa a dotacions amb rendes percebudes per participacions en imposicions municipals, com els 100.000 sous produïts per 6 "setzenes" sobre els "drets de quartera" a la plaça del Blat, amb què el secretari reial Guillem Oliver, promotor d'una de les capelles de la Seu, va dotar el seu benefici l'any $1384^{23}$. Tot i això, els fundadors d'aquell període continuaven decantant-se pel sistema de finançament tradicional, el cens emfitèutic, percebut preferentment sobre immobles urbans, de manera que bona part dels habitatges barcelonins d'aleshores estaven vinculats a un o altre dels beneficis fundats en les esglésies de la ciutat.

\section{III.2. Finançament de la capella}

Aquest element, també necessari per a la celebració del culte, requeria un finançament diferent al de la manutenció del beneficiat. La primera raó d'això és que, mentre que l'atorgament del dot beneficial era indispensable per a la fundació d'un benefici, en canvi, el finançament d'una capella constituïa un compromís opcional, ja que existia l'alternativa de sol-licitar permís a l'autoritat eclesiàstica per a fundar-lo en una capella on ja hi hagués altres beneficis, encara que estiguessin dedicats a una altra advocació. La segona, és que, mentre que la manutenció d'un beneficiat era una obligació contreta a llarg termini i que, per tant, requeria una inversió inicial per aconseguir unes rendes perpètues, en canvi, el donatiu atorgat per una capella s'havia d'efectuar en el decurs d'un curt termini i en metàl-lic, ja que es precisaven els diners per a construir-la o, simplement, per a poder continuar les obres globals de l'església.

Com ja s'ha dit, les crisis que es van produir durant aquell període no van afectar tothom, de manera que el sector més privilegiat, tal com havia adquirit títols de deute públic o participacions sobre recaptacions municipals, també va adquirir drets sobre part de les esglésies que s'estaven construint. El sistema d'adquirir-los consistia a adreçar una sol-licitud a

"2ADB. Registra Dotaliarum, 2, fols. 594 r. -597 v.

$\therefore$ ACB, Notaria particular. F.de Montalt, 263, s.f.. abril del 1383. 
l'autoritat eclesiàstica competent perquè concedís una capella en l'església desitjada i poder instituir en ella un benefici en honor del sant escollit, tal com explica que ho va fer Jaume de Rocafort, a qui ja ens hem referit, en l'acta de dotació del seu benefici ${ }^{2+}$ :

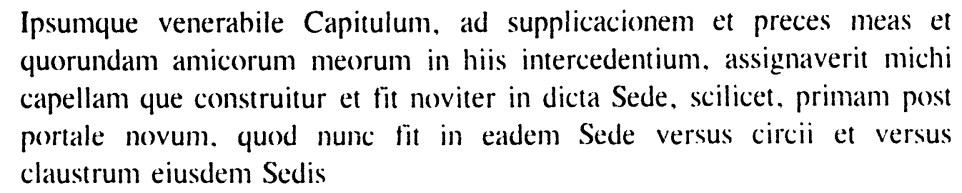

Com a contrapartida, el sol-licitant es comprometia amb aquella autoritat a atorgar una quantitat de diners suficient per al seu finançament $o$, si ja estava construïda la que sol·licitava, per al finançament d'una altra que només estigués projectada, per la qual, arribat el moment, pagaria un altre fundador. Segons la documentació notarial i els llibres d'obra de la Seu, aquells donatius oscil-laven entre les 100 lliures per una capella del claustre de la Catedral i les 50 amb què s'obtenia una capella a Santa Maria del Mar. Amb aquest sistema es va aconseguir que, tot i les dificultats, no s'arribessin a aturar les ampliacions de la Seu i les esglésies parroquials per manca de diners.

La documentació eclesiàstica conservada en relació al finançament d'aquelles capelles és molt escassa, ja que s'han perdut els registres dels ingressos i despeses relatius a la construcció de les esglésies parroquials intramurs, així com bona part dels llibres d'obra de la Seu de la primera meitat del segle XIV. En conseqüència, les úniques capelles amb el procés de finançament ben documentat són les situades en les ales del claustre de la Seu contigua i perpendicular a l'església. A través d'aquestes escasses notícies $i$, sortosament, de la informació paral-lela que aporta la documentació notarial, s'observa que la manera com se solia efectuar el pagament d'aquelles capelles no era al comptat, sinó a terminis. Sembla que succeïa el mateix amb els finançaments de capelles ordenats en testaments, de manera que el fet de poder disposar del llegat atorgat per aquell concepte no deuria implicar, necessàriament, haver de pagar la capella al comptat. Per exemple, la capella que Guillem Almogàver va ordenar promoure a la Catedral en el seu testament va ser pagada en més d'un termini, tal com es

\footnotetext{
${ }^{24}$ ADB. Registra Dotaliarum, 1. fol. 331 r.. 2-1-1353.
} 
veu en l'àpoca signada pel procurador de l'obra de la Seu als seus marmessors l'any 1367, on consta que ha rebut 50 de les 100 lliures ( 20 sous $=1$ lliura aprox.) llegades per aquell concepte ${ }^{25}$ :

confiteor et recognosco vobis (...). manumissoribus testamenti dicti Guillelmi Almugaver, quondam, quod solvistis michi (...) mille solidos ex illis duobus mille solidos quos dictus Guillelmus Almugaver dari mandavit operi dicte Sedis pro una capella sibi assignanda de capellis novis Sedis predicte

\section{III.3. Finançament dels ornaments beneficials}

Entre aquests ornaments trobem, d'una banda, els que resultaven indispensables per a la celebració del culte, com la indumentària litúrgica del beneficiat, el calze, la patena o el missal, i de l'altra, els que contribuïen a l'embelliment de la capella, com taules, frontals d'altar, tapissos i retaules. Com ja s'ha dit, no resulta del tot clar si la donació d'ornaments prescindibles per a la celebració del culte, concretament la del retaule, constituïa un dret o una obligació, tant per part dels fundadors com dels beneficiats vinculats a capelles on no n'hi havia o s'havia fet malbé.

El retaule constitueix un cas a part entre tots els ornaments beneficials, tant pel seu cost i les seves dimensions com per la seva funció. Aquesta funció era la de ser un suport on visualitzar els episodis més exemplaritzants de la vida i miracles del sant o sants venerats en la capella. La proliferació de capelles gairebé particulars en les esglésies, així com la dels retaules en elles, representen la culminació d'un mateix fenomen, que es va manifestar intensament durant aquell segle: la tendència a la privatització del sentiment religiós i la seva concreció en la veneració del sant escollit pel fidel com a protector i intercessor davant Déu. D’aquí els escuts familiars que encara ara sobresurten de murs de capelles i guardapols de retaules, i també les figures de donants agenollats als peus dels sants pintats en ells, tot i que podem suposar que les petites vanitats dels comitents hi van tenir tant a veure com la tendència a la privacitat del seu sentiment religiós.

L'import dels retaules encarregats en nom d'aquells beneficis era molt variat, aproximadament entre les $45 \mathrm{i}$ les 110 lliures segons les àpoques i els contractes conservats, publicats en gran part per Madurell, com les 45

\footnotetext{
25 AHPB. F. de Ladernosa. 23/2. fol. 70 r.. 14-10-1367.
} 
pagades a Pere de Valldebriga pel retaule de sta. Maria Magdalena de la Seu l'any $1370^{26}$ o les 110 pagades pel dels sants Tomàs i Antoni de P., també de la Seu, a Pere Serra i Joan Mates l'any 1409. ${ }^{27}$ Sembla que el pagament d'aquestes obres no es realitzava mai al comptat, sinó a terminis. L'adopció d'aquest sistema no està justificada exclusivament per l'import dels retaules, ja que el preu dels destinats a les capelles laterals de la Seu i les esglésies parroquials, per les seves dimensions, no solia sobrepassar les 50 lliures. L'explicació rau, doncs, en el fet que es tractava d'obres contractades amb particulars, amb artesans, molt més exposats al perill de deixar-les inacabades del que podia estar-ho una junta d'obra parroquial o el capítol catedralici en construir una capella. La forma més habitual de fraccionar el seu pagament era en tres terminis del mateix import: el primer es pagava en el moment de contractar el retaule. per tal que el pintor pogués comprar els materials necessaris; el segon, quan el suport de fusta estava preparat per a rebre la pintura, és a dir, endrapat, enguixat, dibuixat i amb el pa d'or disposat i ja punxonat; finalment, el tercer, quan el pintor lliurava l'obra acabada 0 , segons les condicions establertes en el contracte, quan l'havia collocat a la paret de la capella.

\section{SUPPERVISIÓ DE L.'IESTAT DE LA CAPELLLA,}

\section{IEL FUNCIONAMENT DIEL, BENEFICI I IEL COMPORTAMIENT DEL, BENEFICIAT}

La supervisió del funcionament i l'estat de les esglésies de la diòcesi es realitzava a través de les visites pastorals, efectuades pel bisbe o el seu nunci. Totes les observacions relatives als beneficis existents en les capelles de cada església (rendes, ornaments, beneficiats) eren enregistrades en els llibres de visita pastoral. Malauradament no són gaires els registres del segle XIV conservats en relació a la Seu i les esglésies parroquials barcelonines estudiades, però proporcionen una informació tan interessant que ho compensa: es tracta de l'estadi en què es trobava l'enderroc dels edificis romànics i la construcció dels gòtics en el moment de cada visita. A través del recorregut seguit pel visitador es pot conèixer quines capelles havien estat construïdes i quines enderrocades des de la visita anterior, ja que els

\footnotetext{
*Vid. nota núm. 13.

:7osep Mat Madurlitl. ol). (it.. I. p. 323. doc. 304.
} 
beneficis que hi havia apareixen repartits entre els altars d'altres capelles noves o ubicats temporalment en alguna de les estances que integraven la construcció romànica, com, per exemple, el celler en el cas de la Seu ("domum que vocatur lo celler, in qua sunt octo altaria") ${ }^{28}$. La visita es realitzava capella per capella $i$, dins de cadascuna, benefici per benefici. S'inspeccionava la documentació relativa a la fundació del benefici, i s'anotava en el llibre de Visita el nom del seu fundador, la data en què va ser instituït i el notari amb qui es va redactar l'acta de dotació i, si s'havia perdut, també es feia constar, com succeïa l'any $1421 \mathrm{amb}$ el benefici que havia fundat Joan Sabastida a la Seu el 1388, per al qual va donar un retaule ${ }^{29}$ :

\footnotetext{
Vacuit dotaliam factam per Johannem Ça Bastida, civem Barchinone. in posse discreti Petri de Ortis, notari publici Barchinone, decima die julii anno millesimo $\mathrm{CCC}^{\circ}$ octuagesimo octavo
}

També es feien constar la procedència i l'import de les rendes percebudes per cada benefici i la part que en corresponia al beneficiat anualment. Igualment, es dedicava un breu comentari a la conducta dels beneficiats, tant en relació al benefici com a la seva vida privada: "dixit que ha oÿt dir que té una dona a casa", es deia d'un beneficiat de Sant Just l'any $1390^{30}$, o "ha oÿt dir que's toyl de vin a vagades", es comentava d'un altre de Santa Maria del Mar".

Finalment, es revisaven els ornaments pertanyents a cada benefici de la capella (calzes, missals, casulles, pal-lis, frontals) i, quan presentaven algun escut, o bé s'identificava la família a què pertanyia ("cum signo de Oliver", "ab armes de Cardona" etc.) o bé se'n descrivia l'emblema ("cum signo in medio de rochs", "ab senyal de ferradura", etc.). En aquesta revisió de la capella i els ornaments també es destacava l'estat de conservació en què es trobaven, de vegades molt negligit, com el de la capella del Corpus de Sta. Maria del $\mathrm{Pi}^{32}$ :

\footnotetext{
${ }^{28}$ ADB, Visites Pastorals, 9. 1388, Seu, fol. 21 v.

2"ADB, Visites Pastorals, 12, 1421, Seu, fol. 45 r.

"ADB. Visites Pastorals. 9. 1390. Sant Jisi. fol. 112 v.

"Ibicl., Santa Maria del Mar, fol. $138 \mathrm{r}$.

32ADB, Visites Pastorals, 7, 1379. Sta. Maria del Pi, fol. 21 v.
} 
fuit inventa (la capella) tota polsosa et terenyinosa et lo reataula terenyinors

En els llibres de visita anteriors al segle XV el retaule no era objecte de cap comentari especial, si no era en relació a la seva inexistència: "in dicta capella non est retrotabulum", es deia de la capella del Corpus de Santa Maria del Mar l'any $1402^{33}$, o a l'incompliment del compromís d'encarregar-ne un per part d'algun fundador, com succeïa a la capella dels sants Tomàs i Antoni de P. de la Seu (recordem l'ordre donada, l'any 1388, que "vocetur en Rochafort"). En canvi, a partir d'aquell segle, les descripcions dels retaules en aquells registres comencen a ser cada cop més exhaustives, tot i que, malauradament, sovint es refereixen a obres que van reemplaçar les realitzades durant el període que ens ocupa. Però la identificació dels retaules anteriors al segle XV entre les descripcions d'obres ja posteriors no resulta excessivament difícil, ja que sovint se'ls dedicava el qualificatiu de "valde antiquum" i fins i tot els de "antiquum et indecens", valoracions que contrasten amb les de "de novo depictum", "satis pulcrum" o "pulcherrimum" dedicades als retaules més nous.

\section{POSSIBLES SITUACIONS DEL BENEFICI AL LLARG DEL TEMPS}

El benefici era un ens susceptible d'experimentar molts canvis al llarg de la seva existència. Per començar, podia ser traslladat, fins i tot diverses vegades, des del seu emplaçament originari a altres llocs. La translació de beneficis d'un lloc a l'altre va ser especialment habitual a Barcelona durant el segle XIV, a causa del progressiu enderroc de capelles que s'anava produint a la Seu i les esglésies parroquials a mesura que avançava la construcció de les obres noves. En el millor dels casos, els beneficis afectats per la desaparició del seu altar podien ser traslladats directament a una capella nova que hagués estat erigida sota la mateixa advocació, però, de vegades, havien de romandre bastant temps en un lloc provisional fins que es decidia la seva destinació definitiva, com va succeir amb els beneficis aplegats al celler de l'antiga Seu romànica. De vegades el trasllat també podia ser ordenat per l'autoritat eclesiàstica a causa de l'acumulació de beneficis en una capella i les dificultats que se'n derivaven

\footnotetext{
${ }^{33}$ ADB, Visites Pastorals, 6, 1402, Sta. Maria del Mar, fol. 50 r.
} 
per a la celebració del culte, com succeïa a la de santa Maria i santa Eulàlia de la Seu l'any $1369^{34}$ :

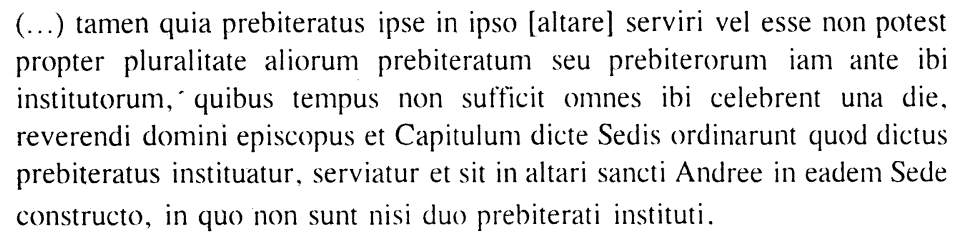
propter pluralitate aliorum prebiteratum seu prebiterorum iam ante ibi institutorum,' quibus tempus non sufficit omnes ibi celebrent una die. reverendi domini episcopus et Capitulum dicte Sedis ordinarunt quod dictus prebiteratus instituatur, serviatur et sit in altari sancti Andree in eadem Sede constructo, in quo non sunt nisi duo prebiterati instituti.

De la mateixa manera, el benefici podia experimentar canvis d'advocació, com va succeir-li al de la Santíssima Trinitat i santa Apol·lònia instituitt l'any 1331 per Saurina Durfort a Santa Maria del Mar, advocació que va ser mudada per la de sant Simeó i santa Apol-lònia quan es va construir una capella dedicada específicament a la Santíssima Trinitat en aquella església, l'any $1339^{35}$. El benefici també podia experimentar vacants, períodes en què, després de la mort d'un beneficiat i d'haver publicat la convocatòria pertinent, s'estava a l'espera de l'aparició d'un candidat que reunís els requisits estipulats pel fundador. Igualment, al cap de segles de la seva fundació, podia ser objecte d'unions amb altres i de supressions, possiblement perquè, si la descendència del fundador no s'havia ocupat d'anar-ne actualitzant les rendes, al final amb aquell benefici no es podia mantenir cap beneficiat. Després de suprimir aquells beneficis, l'autoritat competent tenia diverses opcions. Per exemple: el quart benefici de sant Nicolau de la Seu, fundat l'any 1329, "fuit suppressum et unitum mensa capitulari cum pracitata gregoriana kalendatio in primo beneficio capelle beate Marie et sancta Eulalia"36, així com el primer de santa Cecília, el primer de sant Martí i el segon de sant Jaume, tots anteriors al 1300. En canvi, el benefici de santa Agnès fundat l'any 1385 a la capella de sant Rafael de Santa Maria del Mar, quan es va suprimir, l'any 1551, va ser unit a l'obra de l'església i les seves rendes aplicades a sufragar l'orgue d'aquella ${ }^{37}$.

\footnotetext{
${ }^{34}$ AHPB, F. de Ladernosa, 23/20, fol. 22 v, 4-5-1369.

${ }^{35} \mathrm{ACB}$, Speculum, II, fol. $50 \mathrm{r}$.

${ }^{36} \mathrm{ACB}$, Speculum, I, fol.151 $\mathrm{r}$.

${ }^{37} \mathrm{ACB}$, Speculum, II, fol. $168 \mathrm{r}$.
} 
Finalment, a part d'aquestes possibles situacions, el benefici també podia experimentar permutes, ja que, com s'ha dit, hi havia beneficiats inquiets que sol-licitaven permís al patró per a intercanviar el benefici que se'ls havia assignat amb el d'un altre beneficiat o bé amb l'ofici d'algun prevere, per exemple la rectoria d'una església. La documentació notarial proporciona algunes notícies al respecte, com el permís concedit per la patrona del benefici dels sants Marc i Bàrbara fundat a Santa Maria del Mar, l'any 1367 , al seu beneficiat ${ }^{38}$.

"(...) ego Maria, uxor venerabilis Petri de Molleto (...), patrona illius primi prebiteratus quem dictus maritus meus ordinavit seu dotavit in altari sancti Marchi et sancte Barbere constructo in ecclesia Sancte Marie de Mari civitatis Barchinone, attendens Guielmum de Calabuig, dicti beneficii beneficiatum, velle ipsum beneficium canonice permutare cum ecclesia Sancti Stephani de Castellario diocesis Barchinone, quam obtinet Guillelmus Cerola, rectorem eiusdem ecclesie (...) ordino vos (...) procuratorem meum certum ad comparendum coram reverendo in Christo Patre et Domino domino barchinonense episcopo (...) et ad presentandum eidem domino domino episcopo (...) dictum Guillelmum Cerola ad beneficium prelibatum

A través d'aquesta breu aproximació al funcionament del sistema beneficial en la Barcelona del segle XIV s'ha pretès donar una idea de la riquesa i complexitat del tema, de les seves connexions amb diversos aspectes de l'entorn social, de la diversitat de fonts disponibles per al seu estudi i, per tant, del seu interès. En conseqüència, esperem haver aconseguit justificar la definició del benefici eclesiàstic donada al començament: marc legal de la celebració del culte, mirall del seu entorn i aglutinador de fenòmens tan diversos com la religiositat, l'economia i l'art.

\section{RÉSUMÉ}

Le bénéfice ecclésiastique était une figure juridique, valide à perpétuité, qui avait pour objet de financer la célébration quotidienne du culte dans un autel déterminé, érigé sous l'invocation du saint même à qui était dédié le benefice. Cela requièrait que son fondateur nommait un prêtre dédié exclusivement à la célébration liturgique à cet autel-là, et qui garantissait la perception de rentes sûres et perpétuelles pour sa manutention et celle de son

\footnotetext{
${ }^{38}$ AHPB, G. de Santilari. 20/9, fol. 37 r, 11-1-1367.
} 
successeur. De la même manière, il était nécessaire de disposer d'une chapelle où eriger l'autel auquel attaché le bénéfice, et aussi il était très recommendable qu'il y ait un rétable où puissent apparaître visualisés la vie et miracles du saint qui était là vénéré. À l'époque de la Barcelona du XIV $\mathrm{XV}^{\mathrm{e}}$ siècle, dans un contexte de rénovation globale de la ville, il se produisit la démolition graduelle de la catédrale et les trois grandes églises parroquiales romaniques et leur substitution par des nouveaux temples gotiques. Face aux difficultés financières auquelles ces oeuvres-ci durent se confronter, les autorités ecclésiastiques optèrent pour concéder à la personne chaque nouvelle chapelle qu'elle voulait fonder en elle un bénéfice. en échange d'une substantielle donation. De cette façon, tandis que les rentes assignées au bénéfice, obtenues à travers plusieurs systèmes, l'attachaient au fonctionnement économique de son environnement, le financement des chapelles et rétables l'attachait à son nom à la promotion artistique. Pour tout cela, l'intérét du bénéfice ne se trouvait que dans le cadre légal de la célébration du culte, sinon qu'il représentait la conjonction des phénomènes aussi importants et divers comme la religiosité, l'économie et l'art.

\section{SUMMARY}

The ecclesiastical benefice was a legal body, valid for perpetuity, whose aim was to finance the daily celebration of the cult in a specific alter, erected under the same invocation as the saint to whom the benefice was dedicated. This required its founder to name a priest exclusively dedicated to liturgical celebration at that alter, that would for ever guarantee a private income for him and his successors. It was also necessary to have access to a chapel where the alter that would be linked to the benefice could be erected, and adviseable for the alter piece to visualize the life and miracles of the saint that was being revered. In XIVth century Barcelona, within a context of the city's global renovation, there took place the gradual demolition of the cathedral and the three great Romanesque parish churches and their replacement by new Gothic temples. The financial difficulties faced by these works resulted in the ecclesiastical authorities deciding to grant each new chapel to the person who wished to fund a benefice in it, in exchange for a substantial donation. In this way, whilst the private income assigned to the benefice, obtained via numerous systems, linked it to the economic functioning of its surroundings, the financing of the chapels and alter pieces linked them to artisteic advancement by name. Thus, the interest of the benefice is not only situated in the legal framework of the cult's celebration, but in its representation of such important and different phenomena such as piety, economy and art. 